\title{
New features for Powder Diffraction
}

Powder Diffraction has published several issues and sections on representative papers from international X-ray conferences, namely the Denver X-ray Conference and Chinese National Conference on X-ray Diffraction and ICDD Workshop. These collaborations have provided our readers with more high quality articles and insight into these conferences.

Since the response from the X-ray and materials science communities has been positive, ICDD Board of Directors recently agreed to increase the number of Powder Diffraction issues from four to five per year. As a result, a fifth issue on representative papers from an international X-ray conference will be added as a supplementary issue attached to a regularly scheduled quarterly issue (March, June, September, or December).

The first supplementary issue will be published with the June 2008 issue, representing papers from the Latin American Workshop on Applications of Powder Diffraction and Mini-Course on Methods of Powder Diffraction, which was held April 16-20, 2007 in Campinas, Brazil. The articles, written primarily by scientists in Latin America, cover many areas of powder diffraction applications, such as crystal structure and microstructure of bulk and thin film materials by X-ray and synchrotron radiation.

By publishing papers from international X-ray conferences in Powder Diffraction, authors and attendees can showcase their experiments and findings to a larger audience, and our readers can learn more about X-ray activities from around the world.
Powder Diffraction will be transitioning to a new online, web-based manuscript submission and peer review system hosted by the American Institute of Physics' (AIP) Peer $\mathrm{X}$-Press (PXP) service. PXP is an editorial management service that provides electronic processing of manuscripts from author submission to manuscript review, revision, and final approval. Although we currently process and handle submission electronically by e-mail and internet, we want to fully automate the editorial process and speed up the publication of papers.

AIP's PXP system is a reliable and proven editorial tool that can help us achieve automation and speed. With PXP, reviewers and editorial staff can expedite the editorial peerreview process, track articles throughout the review process, generate reports, and decrease time to publication. Authors will benefit from a system that automates the manuscript submission process; the status and editorial progress of a submitted paper can be checked immediately anytime and anywhere with internet access.

It is our hope that a new, quicker, and user friendly editorial process will benefit Powder Diffraction authors, editorial staff, and readers. We hope to have the system up and running by the third quarter of this year. More information about the submission and editorial process will be presented then.

Ting C. Huang Editor-in-Chief 